\title{
Correction to: Critical Comparison of Liquid Chromatography Coupled to Mass Spectrometry and Three Different Ion Mobility Spectrometry Systems on Their Separation Capability for Small Isomeric Compounds
}

\author{
Tobias Werres $^{1,2} \cdot$ Juri Leonhardt ${ }^{3} \cdot$ Martin Jäger $^{2} \cdot$ Thorsten Teutenberg $^{1}$ (I)
}

Published online: 5 July 2019

๑) Springer-Verlag GmbH Germany, part of Springer Nature 2019

\section{Correction to: Chromatographia (2019) 82:251-260 \\ https://doi.org/10.1007/s10337-018-3640-z}

Unfortunately a second footnote (Published in the topical collection 24th International Symposium on Separation Sciences ...) was added to the original submission.

The valid footnote is: Published in Chromatographia's 50th Anniversary Commemorative Issue.

Publisher's Note Springer Nature remains neutral with regard to jurisdictional claims in published maps and institutional affiliations.

The original article can be found online at https://doi.org/10.1007/ s10337-018-3640-z.

Thorsten Teutenberg teutenberg@iuta.de

1 Institut für Energie- und Umwelttechnik e. V., Bliersheimer Str. 58-60, 47229 Duisburg, Germany

2 Instrumental Analysis, Niederrhein University of Applied Science, Frankenring 20, 47798 Krefeld, Germany

3 CURRENTA GmbH \& Co. OHG, Alte Heerstraße, 41538 Dormagen, Germany 